Acta Agroph., 2020, 27, 5-16

doi: $10.31545 /$ aagr/125721

\title{
ESTIMATION OF QUALITY OF SPAGHETTI-FORM COMMERCIAL GLUTEN-FREE PASTAS
}

\author{
Jakub Kosiński ${ }^{1}$ [), Grażyna Cacak-Pietrzak ${ }^{2}$ (1) \\ ${ }^{1}$ Department of Fruit and Vegetable Processing Technology, Prof. Wacław Dąbrowski Institute \\ of Agricultural and Food Biotechnology, ul. Rakowiecka 36, 02-532 Warszawa, Poland \\ ${ }^{2}$ Division of Fruits, Vegetables and Cereals Technology, Warsaw University of Life Sciences \\ ul. Nowoursynowska 159C, 02-787 Warszawa, Poland \\ e-mail: jakub.kosinski@ibprs.pl
}

\begin{abstract}
The objective of the study was the estimation of quality of spaghetti-form commercial gluten-free pastas with diversified raw material composition. The experimental material consisted of 9 pastas, including 7 gluten-free pastas and 2 wheat pastas (from semolina and from flour from common wheat grain) which constituted the control sample. The packaging was evaluated for correct labelling, and the content of crumble was determined. The content of basic chemical components was assessed, such as water, total protein, mineral components (ash). Culinary and sensory evaluation of the pastas was carried out. It was found that a majority of the gluten-free pastas, except for the buckwheat pasta, contained significantly less total protein, which translated into greater loss of dry matter during their cooking. In terms of sensory features, pastas made of rice flour and from a mixture of maize and rice flour were highly rated, while the buckwheat pasta was definitely rated the lowest.

Keyw ords: gluten-free pasta, chemical composition, culinary quality, sensory properties
\end{abstract}

\section{INTRODUCTION}

Pastas are among those cereal products that are commonly consumed around the world. The factors that determine the popularity of pastas include e.g. the broad assortment of the products, relatively low price, long shelf life and ease of storage, and extensive possibilities of the preparation of meals resulting from their neutral taste. Pastas are a good substitute for bread, potatoes, groats, rice, can be used as an additive to soups, main courses, salads or desserts (Carini et al. 2013, Bustos et al. 2015, Rafiq et al. 2017, Littardi et al. 2019). The market offers a broad range of pastas with diverse raw material composition, length and shapes. Apart from the most popular wheat pastas, there are also pastas made from other cereal materials, including gluten-free pastas (Giuberti et al. 2015, Kahlon and Chiu 2015, Palavecino et al. 2017, Cacak-Pietrzak and Rajkowska 2019). 
Gluten-free pastas are produced mainly for consumers with gluten intolerance. Over the past several years there is been an increase in the number of persons with diagnosed coeliac disease, hypersensitivity to gluten or wheat. It is estimated that about $1 \%$ of the world population suffers from coeliac disease (Lamacchia et al. 2014). The basis for the treatment of gluten-dependent diseases is total elimination of products containing gluten proteins from the diet. Restrictive diet must be observed throughout the lifetime of the patient (Lamacchia et al. 2014, Bustos et al. 2015). According to the Food and Drug Administration (FDA), the maximum content of gluten in commercial gluten-free products cannot exceed $20 \mathrm{mg} \mathrm{kg}^{-1}$ of the product in the form in which it is marketed (Kahlon and Chiu 2015). The same maximum level of gluten in gluten-free products has been defined in the Commission Implementing Regulation No. $828 / 2014$ of $30^{\text {th }}$ July, 2014, on the provision of information to consumers on the absence or reduced presence of gluten in food. This is the lowest level that can be assayed in food products with the use of the current analytical methods. Products meeting this requirement can be labelled as "gluten-free product" and "does not contain gluten" (Regulation 2011, Rosell et al. 2014, Kahlon and Chiu 2015).

Raw materials used for gluten-free pasta production include rice flour, maize flour, buckwheat flour, millet flour, soy flour, quinoa flour, amaranth flour, teff flour, as well as starches of diverse origin (e.g. maize starch) (Alvarez-Jubete et al. 2010, Schoenlechner et al. 2010, Zannini et al. 2012, Lamacchia et al. 2014, Rosell et al. 2014, Giuberti et al. 2015, Kahlon and Chiu 2015, Ferreira et al. 2016). Due to the absence of gluten proteins in those raw materials, the process of pasta production is more difficult. There are also problems with creating a product with culinary and sensory properties acceptable to the consumers. During the cooking of gluten-free pastas large amounts of dry matter migrate to the solution, and after the cooking the pastas often tend to stick (Schoenlechner et al. 2010, Zannini et al. 2012, Marti and Pagani 2013, Ferreira et al. 2016). Certain producers use emulsifiers (lecithins, monoand diglycerides of fatty acids, mono- and diglycerides of fatty acids esterified with organic acids) as a recipe admixture to gluten-free pastas. The addition of emulsifiers improves the rheological properties of dough - reduces its springiness, increases its elasticity and plasticity, thanks to which the adhesiveness of the dough to rolling and forming equipment decreases. Emulsifiers, especially those with medium and long carbohydrate chains, inhibit the swelling of starch granules. In addition, forming complexes with starch, they reduce its solubility and susceptibility to the effect of enzymes. The formation of emulsifier-starch complexes affects the degree of starch gelatinisation. In the presence of emulsifiers, starch granules, especially the amylose fraction, are bound with denaturated proteins, which reduces dry matter losses during cooking and the viscosity of pasta (Obuchowski 1997, Schoenlechner et al. 2010, Marti and Pagani 2013). Similar results can be obtained by introducing hydrocolloids, e.g. xanthan gum, as an ingredient of gluten-free pastas (Schoenlechner et al. 
2010, Zandonadi et al. 2012, Zannini et al. 2012, Marti and Pagani 2013), modified starches, or egg whites (Schoenlechner et al. 2010, Zannini et al. 2012, Kahlon et al. 2013, Palavecino et al. 2017).

The objective of the study was the estimation of selected commercial spaghetti-form gluten-free pastas with diversified raw material composition and their comparison with wheat pastas, the most frequently purchased and consumed.

\section{MATERIAL AND METHOD}

\section{Experimental material}

The experimental material consisted of 9 spaghetti-form commercial pastas, diversified in terms of raw material composition (Tab. 1), originating from two different production batches. Among the analysed pastas, 7 were produced from gluten-free raw materials. The control sample consisted of two wheat pastas (from semolina and from flour from the grain of common wheat). Two of the gluten-free pastas were of Polish production, the remaining ones were imported. Prior to the evaluation of the quality of the pastas, their packaging was checked for correct labelling (Regulation 2011, 2014).

Table 1. List of pasta tests, their origin and composition

\begin{tabular}{|c|c|c|c|}
\hline $\begin{array}{l}\text { Sample } \\
\text { number }\end{array}$ & $\begin{array}{l}\text { Country } \\
\text { of origin }\end{array}$ & Ingredients & $\begin{array}{l}\text { Cooking time } \\
\quad(\min )\end{array}$ \\
\hline \multicolumn{4}{|c|}{ Gluten-free pasta } \\
\hline 1 & Poland & $\begin{array}{l}\text { maize flour, rice flour, mono- and diglycerides of fatty } \\
\text { acids, water }\end{array}$ & $11-12$ \\
\hline 2 & Poland & maize flour, water & $10-11$ \\
\hline 3 & Germany & buckwheat flour, water & $8-10$ \\
\hline 4 & Italy & maize flour, rice flour, water & $10-12$ \\
\hline 5 & Italy & maize flour, rice flour, water & $10-12$ \\
\hline 6 & Netherlands & black rice flour, brown rice flour, water & $5-6$ \\
\hline 7 & Netherlands & brown rice flour, water & $5-6$ \\
\hline \multicolumn{4}{|c|}{ Wheat pasta } \\
\hline 8 & Greece & durum semolina, water & $12-14$ \\
\hline 9 & Czech Republic & wheat flour, water & $10-12$ \\
\hline
\end{tabular}

Methods of estimation of physicochemical and physical properties of pasta

The basic physicochemical properties of the pastas were determined as follows: moisture - with the dryer method, using a SUP-65W fryer from the company Wamed (PN-EN ISO 712:2012), total protein content - with the Kjeldahl method $(\mathrm{N} \cdot 5,7)$ in the Kjeltec 8200 apparatus from Foss (PN-EN ISO 20483:2014-02), total ash content - with the method of incineration in a FCFS muffle furnace from 
the company Czylok (PN-ISO 2171:2010), crumble content (PN-93/A-74130: 1993) and hardness with the use of the TA.XT2i texture analyser, StableMicro System. For hardness measurement the compression test was applied, using a head with nominal force of $0.05 \mathrm{~N}$, travel/feed rate of $0.1 \mathrm{~mm} \mathrm{~s}^{-1}$ (Operation Manual).

\section{Methods of pasta quality analysis after cooking}

Pasta samples with weight of $100 \mathrm{~g}$ were cooked in $1000 \mathrm{~cm}^{3}$ of water for a time declared by the producer on the packaging. After straining, the pasta was weighed, the value of the weight increase index was calculated, and dry matter losses during cooking were determined (Obuchowski 1997). Sensory evaluation of the pasta was performed by a 15-person team of consumers. It comprised the evaluation of the appearance (colour, shape), flavour and taste of the pasta. Each of those features was evaluated in the scale from 1 (least desirable) to 5 points (most desirable).

\section{Statistical analysis}

Every determination was made in four replicates. The statistical analysis was performed using the program Statistica 13. One-factor analysis of variance was applied. The significance of differences between mean values was determined using the Tukey test at significance level of $\alpha=0.05$. The results of the determinations were given as means for the two production batches of pasta.

\section{RESULTS AND DISCUSSION}

The packaging of the pastas was aesthetic, made of transparent polyethylene film, thanks to which the product inside was clearly visible. The labelling on all products contained the obligatory information specified in the Regulation of European Parliament and Council (EU) No. 1169/2011 of $25^{\text {th }}$ October, 2011, on providing the consumers with information on food products (Regulation 2011). All gluten-free pastas (samples No. 1 to No. 7) were marked with the graphical sign "Crossed Ear" and the registration number of the product, as well as additional graphical symbols informing that the product did not contain wheat.

Moisture is one of the more important parameters that determine the shelf life of pasta (Obuchowski 1997, Ruszkowska and Nowicka 2017). According to the standard PN-A-74131:1999, the maximum moisture of dry pasta should not exceed $12.5 \%$. Higher moisture can be conducive to the growth of moulds. Pasta moisture should also not be excessively low, as at moisture levels below $6 \%$ pasta becomes more brittle, which increases the content of crumble (Ruszkowska and Nowicka 2017). The moisture of the analysed pastas, both gluten-free and wheat ones, conformed with the requirements of the standard and ranged from 8.3 to $11.0 \%$ (Tab. 2). 
The highest water content was characteristic of the maize-rice pastas (samples No 1 and 4). The lowest amount of water was assayed in the buckwheat pasta (sample No. 3) and the maize pasta (sample No. 2). Compared to the wheat pastas, in terms of this parameter only the maize-rice pasta (sample No. 1) differed statistically significantly. Water content in the commercial gluten-free pastas analysed by Ruszkowska and Rogowska (2015) was somewhat higher (10.1-11.9\%). In an earlier study conducted at the Division of Cereals Technology, Warsaw University of Life Sciences (Cacak-Pietrzak and Rajkowska 2019), water content in fusilli form gluten-free pastas ranged from 7.3 to $8.6 \%$, and an even lower water content level (average of $4.0 \%$ ) was characteristic of commercial buckwheat pastas analysed by Sobczyk and Glige (2012). The control samples had moisture levels similar to those of wheat pastas studied by Cacak-Pietrzak et al. (2016).

Table 2. Results of assessment of the physicochemical and physical properties of pasta

\begin{tabular}{lccccc}
\hline \multirow{2}{*}{$\begin{array}{c}\text { Sample } \\
\text { number }\end{array}$} & Moisture & $\begin{array}{c}\text { Total protein } \\
\text { content }\end{array}$ & Total ash content & Hardness & $\begin{array}{c}\text { Amount of } \\
\text { crushed pasta }\end{array}$ \\
\cline { 2 - 6 } & $\%$ & \multicolumn{2}{c}{$\%$ DM } & $\mathrm{N}$ & $\%$ \\
\hline 1 & $11.0 \pm 0.2^{\mathrm{d}}$ & $7.3 \pm 0.2^{\mathrm{a}}$ & $0.40 \pm 0.01^{\mathrm{b}}$ & $43.6 \pm 3.5^{\mathrm{bc}}$ & $0.4 \pm 0.0^{\mathrm{a}}$ \\
2 & $8.6 \pm 0.7^{\mathrm{ab}}$ & $8.1 \pm 0.7^{\mathrm{ab}}$ & $0.54 \pm 0.03^{\mathrm{c}}$ & $48.2 \pm 3.8^{\mathrm{bcde}}$ & $0.4 \pm 0.4^{\mathrm{a}}$ \\
3 & $8.3 \pm 0.3^{\mathrm{a}}$ & $12.5 \pm 0.2^{\mathrm{d}}$ & $1.71 \pm 0.02^{\mathrm{f}}$ & $70.9 \pm 3.6^{\mathrm{f}}$ & $2.0 \pm 0.2^{\mathrm{ab}}$ \\
4 & $10.1 \pm 0.3^{\mathrm{cd}}$ & $7.6 \pm 0.1^{\mathrm{ab}}$ & $0.50 \pm 0.02^{\mathrm{c}}$ & $45.6 \pm 1.3^{\mathrm{bcd}}$ & $4.1 \pm 0.7^{\mathrm{b}}$ \\
5 & $9.7 \pm 0.2^{\mathrm{bcd}}$ & $7.5 \pm 0.2^{\mathrm{ab}}$ & $0.24 \pm 0.02^{\mathrm{a}}$ & $53.9 \pm 2.2^{\mathrm{e}}$ & $0.5 \pm 0.0^{\mathrm{a}}$ \\
6 & $9.2 \pm 0.4^{\mathrm{abc}}$ & $8.0 \pm 0.1^{\mathrm{ab}}$ & $1.37 \pm 0.04^{\mathrm{e}}$ & $51.7 \pm 3.1^{\mathrm{de}}$ & $0.6 \pm 0.5^{\mathrm{a}}$ \\
7 & $9.6 \pm 0.8^{\mathrm{abc}}$ & $8.1 \pm 0.3^{\mathrm{b}}$ & $1.32 \pm 0.04^{\mathrm{e}}$ & $51.2 \pm 3.7^{\text {cde }}$ & $0.0 \pm 0.0^{\mathrm{a}}$ \\
8 & $9.6 \pm 0.2^{\mathrm{abc}}$ & $11.2 \pm 0.3^{\mathrm{c}}$ & $0.74 \pm 0.01^{\mathrm{d}}$ & $43.3 \pm 0.8^{\mathrm{ab}}$ & $0.3 \pm 0.2^{\mathrm{a}}$ \\
9 & $9.2 \pm 0.9^{\mathrm{abc}}$ & $10.5 \pm 0.3^{\mathrm{c}}$ & $0.38 \pm 0.01^{\mathrm{b}}$ & $37.6 \pm 1.0^{\mathrm{a}}$ & $0.3 \pm 0.0^{\mathrm{a}}$ \\
\hline
\end{tabular}

Values denoted with the same letter indices (a-f) within a column are not statistically significantly different at the level of $\alpha=0.05$.

Protein content is an important parameter affecting the nutritional value, and the culinary and sensory properties of pasta. Pasta with a low protein content is characterised by increased brittleness, and its dry matter losses during cooking are greater (Baiano et al. 2007, Sobota and Skwira 2009, Zandonadi et al. 2012, Bagdi et al. 2014, Ferreira et al. 2016, Joubert et al. 2018, Cacak-Pietrzak and Rajkowska 2019). Total protein content in the analysed pastas varied from 7.3 to $12.5 \% \mathrm{DM}$ and depended significantly on their raw material composition (Tab. 2). The highest content of total proteins was characteristic of the buckwheat pasta (sample No. 3) in which the level of that component was significantly higher compared to the remaining gluten-free pastas, as well as the wheat pastas (control sample). The lowest level of total protein was noted in the maize-rice pastas (samples No. 1, 4 and 5). Total protein content in the wheat pastas (control sample) was $11.2 \%$ DM (semolina pasta) and $10.5 \% \mathrm{DM}$ (common wheat pasta). In the commercial maize-rice 
pastas analysed by Ruszkowska and Rogowska (2015) and by Cacak-Pietrzak and Rajkowską (2019) the content of total proteins was at a level similar to the one in this study (corresponding average values of 7.0 and $7.1 \%$ DM). Somewhat higher levels of total proteins were noted in the gluten-free pastas of rice, sorghum, maize flour and potato starch prepared in laboratory conditions by Ferreira et al. (2016). In wheat pastas analysed by Cacak-Pietrzak et al. (2016) total protein content varied within a broad range, from $10.7 \% \mathrm{DM}$ to as much as $14.7 \% \mathrm{DM}$.

The content of mineral components (total ash content) in the analysed pastas was statistically differentiated and varied from 0.24 to $1.71 \%$ DM (Tab. 2). The highest content of total ash, significantly higher compared to the remaining samples, was characteristic of the buckwheat pasta (sample No. 3). Ash content of also high (1.32 and 1.37\% DM) in brown rice pastas (samples No. 6 and 7). The lowest, significantly lower compared to the other samples, content of total ash was characteristic of one of the maize-rice pastas (sample No. 5). In the wheat pastas, from semolina and common wheat flour (samples No. 8 and 9), total ash content was 0.74 and $0.38 \% \mathrm{DM}$, respectively. Variation of mineral components content in commercial pastas, resulting from differences in raw material composition, is indicated also by the results of earlier studies. In commercial maize-rice pastas (Cacak-Pietrzak and Rajkowska 2019) total ash content was at a level similar to that determined in this study (average of $0.47 \% \mathrm{DM}$ ), while in a buckwheat pasta (Sobczyk and Glige $2012)$ it was nearly double that value $(0.8 \% \mathrm{DM})$. Total ash content similar to that in the study by Sobczyk and Glige (2012) - 0.75-0.87\% DM - was characteristic of gluten-free pastas from sorghum, rice, maize flour and potato starch, prepared in laboratory conditions by Ferreira et al. (2016). In wheat pastas analysed by Romankiewicz et al. (2014), total ash content ranged from 0.66 to $1.02 \%$. An even greater variation of the values of that parameter (from 0.4 to $1.8 \% \mathrm{DM}$ ) is indicated by the results of a study by Martinez et al. (2007) and by Sobota and Skwira (2009).

The hardness of the analysed pastas fell in the range from 37.6 to $70.9 \mathrm{~N}$ and it was statistically significantly differentiated (Tab. 2). The highest hardness, significantly higher compared to the other samples, was characteristic of the buckwheat pasta (sample No. 3) which had the highest levels of minerals and total protein. The lowest hardness was noted in the case of the pasta from flour from the grain of common wheat (sample No. 9). The hardness of the pasta from semolina was 43.3 N. Hardness values comparable to those of the wheat pastas were characteristic of the pasta from maize flour (sample No. 2) and the pastas from mixtures of maize and rice flour (samples No. 1 and 4). The hardness of the wheat pastas analysed by Cacak-Pietrzak et al. (2016) was in the range from $9.9 \mathrm{~N}$ (common wheat pastas) to $58.6 \mathrm{~N}$ (semolina pastas).

According to the standard PN-A-74131:1999, the content of crumble in pastas should not exceed the level of $10 \%$. In none of the analysed pasta samples the content of crumble exceeded the limit specified in the standard, and varied from 0.0 to 
$4.1 \%$, the differentiation being statistically significant (Tab. 2). Such low level of crumble indicates correct packaging, transport and storage of the pastas. No crumble presence was noted in the pasta from brown rice flour (sample No. 7). In both wheat pastas (control sample) the amount of crumble was at the same medium level of $0.3 \%$. The highest content of crumble was noted in one of the maize-rice pastas (sample No. 4) which differed significantly in this respect from the remaining pastas, except for the buckwheat pasta (sample No. 3). In the study by Sobczyk and Glige (2012) the content of crumble in buckwheat pastas was at a level similar to that in our study. In the study by Romankiewicz et al. (2014) the content of crumble in the pastas was maximum $3.0 \%$.

The values of weight increase coefficient, describing the ability of binding water during hydrothermal treatment, varied from 1.96 to 2.55 and were statistically differentiated (Fig. 1). According to Sobota and Skwira (2009), the values of that parameter for wheat pastas should range from 2.0 to 4.0. In this study, the lowest weight increase during cooking (weight increase index below 2.0) was noted for one of the maize-rice pastas (sample No. 4) and the buckwheat pasta (sample No. 3), and the highest - in the case of the wheat pastas (control).

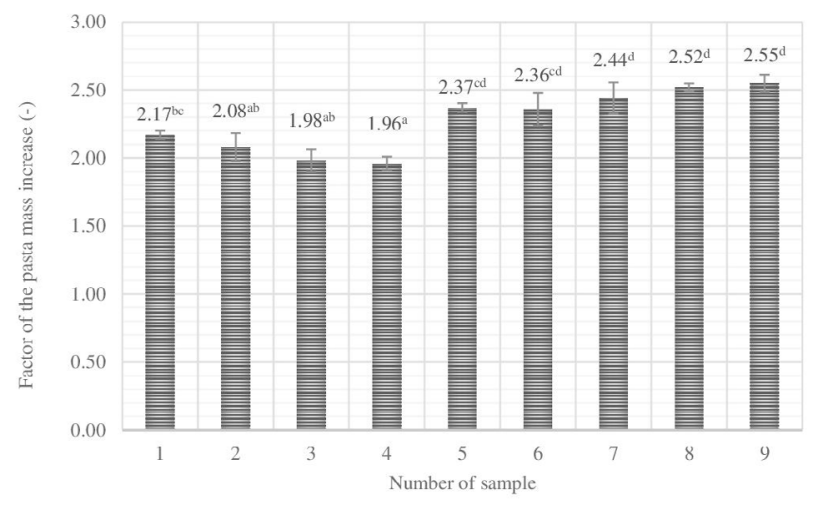

Fig. 1. Coefficient of pasta weight increase during cooking. Values denoted with the same letter indices (a-f) within a column are not statistically significantly different at the level of $\alpha=0.05$.

Weight increase comparable to the wheat pastas was characteristic of the pasta from the mixture of maize and rice flour (sample No. 5) and the pastas from brown rice flour (samples No. 6 and 7). Lower values of the weight increase coefficient compared to the wheat pastas are indicated in the results of studies by Schoenlechner et al. (2010), Ruszkowska and Rogowska (2015), Ferreira et al. (2016), Palavecino et al. (2017), and by Cacak-Pietrzak and Rajkowska (2019). This is caused by the absence of gluten proteins which are characterised by an exceptionally high water binding capacity and ability of forming a spatial gluten lattice which retains gelatinised starch granules, hindering their leaching to water during hydrothermal treatment (Palavecinio et al. 2017). 
Dry matter losses of pasta during hydrothermal treatment varied from 7.47 to $21.03 \%$ and were statistically diversified (Fig. 2). The gluten-free pastas analysed by Palavecino et al. (2017) varied within a narrower range (4.00-10.77\%). According to Deng et al. (2017), the higher the content of gluten proteins in pasta the smaller amount of matter migrates to the water during its cooking. This found support in the results of our study. The smallest amount of dry matter migrated to the water during the cooking of the wheat pastas, both from semolina and from common wheat flour (samples No. 8 and 9). Literature data (Schoenlechner et al. 2010, Kahlon et al. 2013, Marti and Pagani 2013, Ruszkowska and Rogowska 2015, Cacak-Pietrzak and Rajkowska 2019) indicate that the level of dry matter losses of gluten-free pastas can be limited by adding to their ingredients an admixture of hydrocolloids, modified starch, or emulsifiers. This has found support in the results of this study. Dry matter losses of the gluten-free pasta from a mixture of maize and rice flour, the composition of which included mono- and diglycerides of fatty acids (sample No. 1), were at a level comparable to that of the wheat pastas (control sample), both that from semolina and that from common wheat flour. The highest losses of dry matter were noted during the cooking of the buckwheat pasta (sample No. 3) which was characterised by an exceptionally high content of minerals and total proteins, but did not contain any gluten proteins. A study by Sobota and Skwira (2009) shows that during the cooking of pastas with a high ash content dry matter losses are greater as compared to pastas with a lower ash content. The migration of large amounts of dry matter to the water during the cooking of pasta causes that its surface becomes sticky (Schoenlechner et al. 2010, Marti and Pagani 2013).

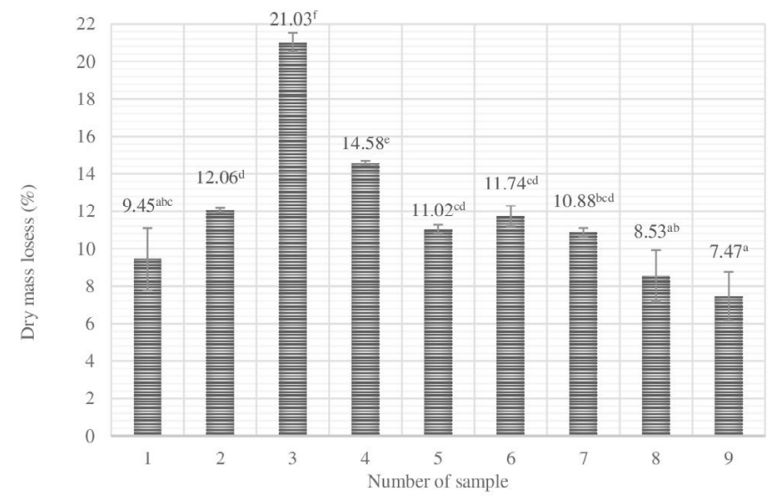

Fig. 2. Dry matter losses of pasta. Values denoted with the same letter indices (a-f) within a column are not statistically significantly different at the level of $\alpha=0.05$.

After cooking, most of the pastas, with the exception of the buckwheat pasta, were characterised by shape typical of the spaghetti form. The colour of the pastas was more diversified - from light creamy (pasta from flour from the grain of 
common wheat), through creamy-yellow (semolina pasta), light yellow (pastas from maize and rice flour), dark yellow (maize pastas), brown (buckwheat pasta), to dark brown (pastas from brown rice flour). The team conducting the sensory evaluation of the pastas gave the highest number of points to the gluten-free pastas from a mixture of maize and rice flour (samples No. 5 and 4), maize flour (sample No. 2), and to the wheat pasta from semolina (sample No. 8) (Tab. 3). All of those pastas were characterised by yellow colour with various hues. The lowest number of points for the colour and shape were given to the buckwheat pasta (sample No. 3). The buckwheat pasta was also rated significantly the lowest in terms of flavour, compared to the other gluten-free pastas and to the wheat pastas. The highest note for flavour was given to the pasta from maize and rice flour (sample No. 5), to the pasta from brown rice flour (sample No. 7), and to both wheat pastas (control sample). The best taste was characteristic of the pasta from maize and rice flour (sample No. 5) and the wheat pasta from semolina (sample No. 8).

Table 3. Results of sensory evaluation of pasta

\begin{tabular}{lcccc}
\hline \multirow{2}{*}{$\begin{array}{l}\text { Sample } \\
\text { number }\end{array}$} & Appearance & Flavour & Taste & Average \\
\cline { 2 - 5 } & \multicolumn{4}{c}{ points } \\
\hline 1 & $3.85 \pm 0.72^{\mathrm{abcd}}$ & $3.92 \pm 0.68^{\mathrm{b}}$ & $3.54 \pm 0.72^{\mathrm{ab}}$ & $3.77 \pm 0.17^{\mathrm{ab}}$ \\
2 & $4.00 \pm 0.52^{\mathrm{bcd}}$ & $3.77 \pm 0.65^{\mathrm{b}}$ & $3.85 \pm 0.52^{\mathrm{abc}}$ & $3.87 \pm 0.10^{\mathrm{a}}$ \\
3 & $3.31 \pm 0.47^{\mathrm{a}}$ & $2.85 \pm 0.50^{\mathrm{a}}$ & $3.23 \pm 0.47^{\mathrm{a}}$ & $3.13 \pm 0.20^{\mathrm{b}}$ \\
4 & $4.08 \pm 0.62^{\mathrm{cd}}$ & $3.62 \pm 0.70^{\mathrm{b}}$ & $3.46 \pm 0.62^{\mathrm{ab}}$ & $3.72 \pm 0.26^{\mathrm{ab}}$ \\
5 & $4.31 \pm 0.60^{\mathrm{d}}$ & $4.23 \pm 0.57^{\mathrm{b}}$ & $4.31 \pm 0.60^{\mathrm{c}}$ & $4.28 \pm 0.04^{\mathrm{a}}$ \\
6 & $3.46 \pm 0.50^{\mathrm{ab}}$ & $3.54 \pm 0.49^{\mathrm{b}}$ & $3.92 \pm 0.50^{\mathrm{abc}}$ & $3.64 \pm 0.20^{\mathrm{ab}}$ \\
7 & $3.46 \pm 0.50^{\mathrm{ab}}$ & $4.08 \pm 0.44^{\mathrm{b}}$ & $4.00 \pm 0.50^{\mathrm{abc}}$ & $3.85 \pm 0.28^{\mathrm{a}}$ \\
8 & $4.00 \pm 0.52^{\mathrm{bcd}}$ & $4.08 \pm 0.57^{\mathrm{b}}$ & $4.15 \pm 0.52^{\mathrm{bc}}$ & $4.08 \pm 0.06^{\mathrm{a}}$ \\
9 & $3.62 \pm 0.47^{\mathrm{abc}}$ & $4.08 \pm 0.57^{\mathrm{b}}$ & $4.00 \pm 0.47^{\mathrm{abc}}$ & $3.90 \pm 0.20^{\mathrm{a}}$ \\
\hline
\end{tabular}

Values denoted with the same letter indices (a-d) within a column are not significantly different statistically at the level of $\alpha=0.05$.

In the sensory evaluation the highest number of points was awarded to the maize-rice pasta (sample No. 5), wheat pasta from semolina (sample No. 8) and the pasta from maize flour (sample No. 2) (Tab. 3). The least points were awarded to the buckwheat pasta (sample No. 3). The colour of that pasta was not uniform, with visible discolorations (spots), its surface was sticky, and there were visible agglutinations. The jurors had reservations concerning the taste and flavour, and in their opinion there was noticeable acidic note to the taste and flavour. In terms of the sensory properties. The remaining gluten-free pastas were more comparable with the wheat pasta from common wheat flour (sample No. 9) than with the pasta from semolina (sample No. 8). 


\section{CONCLUSIONS}

1. Commercial gluten-free pastas, with the exception of the buckwheat pasta, had a significantly lower content of total proteins, compared to the wheat pastas, both from semolina and from flour from the grain of common wheat. Significantly the highest level of total ash was assayed in the buckwheat pasta and in the brown rice pastas. In the pastas from rice flour and from the mixture of maize and rice flour the content of minerals was more similar to their level in the wheat pasta from common wheat flour than in that prepared from semolina.

2 . The analysed pastas were significantly diversified in terms of their culinary properties. The greatest weight increase during cooking, comparable to that of the wheat pastas, was characteristic of the pastas from brown rice and one pasta from a mixture of maize and rice flour. The lowest amount of dry matter migrated to the solution during the cooking of the wheat pastas, both from semolina and from flour from the grain of common wheat. Dry matter losses during the cooking of glutenfree pastas were significantly higher relative to the wheat pastas, with the exception of the pasta from maize and rice flour whose list of ingredients included emulsifiers.

3. Regarding the sensory features of the pastas, the highest notes were awarded to pastas from rice flour, one of the pastas from a mixture of maize and rice flour, and the wheat pasta from semolina. The lowest number of points was awarded to pastas with dark colouring - from buckwheat flour and from brown rice flour, which indicates that the consumers prefer pastas with a light yellow-creamy colouring.

Conflict of interest: The Authors does not declare conflict of interest.

\section{REFERENCES}

Alvarez-Jubete L., Arendt E.K., Gallagher E., 2010. Nutritive value of pseudocereals and their increasing use as functional gluten-free ingredients. Trends Food Sci, Tech., 21, 106-113, https:// doi.org/ 10.1016/j.tifs.2009.10.014

Bagdi A., Szabo F., Gere A., Kokai Z., Sipos L., Tomoskozi S., 2014. Effect of aleurone-rich flour on composition, cooking, textural, and sensory properties of pasta. LWT - Food Science and Technology, 59(2), 996-1002, https://doi.org/10.1016/j.lwt.2014.07.001

Baiano A., Conte A., Pati S., Del Nobile M.A., 2007. Influence of protein content and drying temperature on pasta quality. Tecnica Molitoria International, 58, 84-91.

Bustos MC, Perez GT, Leon AE., 2015. Structure and quality of pasta enriched with functional ingredients. RSC Adv. 5(39), 30780-30792, https://doi.org/10.1039/C4RA11857J

Cacak-Pietrzak G., Rajkowska A.. 2019. Estimation of quality of commercial gluten-free pastas (in Polish). Przegląd Zbożowo-Młynarski, 63(6), 34-37.

Cacak-Pietrzak G., Romankiewicz D., Ceglińska A., Lenart E., 2016. Estimation of quality of commercial fusilli form organic pastas (in Polish). Przegląd Zbożowo-Młynarski, 60(3), 36-39.

Carini E., Curti E., Minucciani M., Antoniazzi F., Vittadini E., 2013. Pasta. In: Engineering Aspects of Cereal and Cereal-Based Products (Eds R.D.P.F. Guine \& P.M. dos Reis Correira). Boca Raton: CRC Press 211-238, https://doi.org/10.1201/b15246-11 
Commission Implementing Regulation No. 828/2014 of $30^{\text {th }}$ July, 2014, on the provision of information to consumers on the absence or reduced presence of gluten in food [Dz. Urz. UE L, 228(5)].

Deng L., Elias E.M., Manthey F.A., 2017. Relationship between grain, semolina, and whole wheat flour properties and the physical and cooking qualities of whole wheat spaghetti. Cereal Chem., 94(5), 801-804, https://doi.org/10.1094/CCHEM-03-17-0064-N

Ferreira S.M.R., De Mello A. P., De Caldas Rosa dos Anjos M., Krüger C.C.H., Azoubel P.M., De Oliveira Alves M.A., 2016. Utilization of sorghum, rice, corn flours with potato starch for the preparation of gluten-free pasta. Food Chem., 191, 147-151, https://doi.org/10.1016/j. foodchem.2015.04.085

Giuberti G., Gallo A., Cerioli C., Fortunati P., Masoero F., 2015. Cooking quality and starch digestibility of gluten free pasta using new bean flour. Cereal Chem., 175, 43-49, https://doi.org/10.1016/j. foodchem.2014.11.127

Joubert M., Morel M.H., Lullien-Pellerin V., 2018. Pasta color and viscoelasticity: Revisiting the role of particle size, ash, and protein content. Cer. Chem., 95, 386-398, https://doi.org/10.1002/ cche. 10038

Kahlon T.S, Chiu M-C M., 2015. Teff, buckwheat, quinoa and amaranth: ancient whole grain glutenfree egg-free pasta. Food Nutri. Sci., 6, 1460-1467, https://doi.org/10.4236/fns.2015.615150

Lamacchia C., Camarca A., Picascia S., Luccia A., Gianfrani C., 2014. Cereal-based gluten-free food: How to reconcile nutritional and technological properties of wheat protein with safety for celiac disease patients. Nutrients, 6, 575-590, https://doi.org/10.3390/nu6020575

Littardi P., Diantom A., Carini E., Curti E., Boukid F., Vodovotz Y., Vittadini E., 2019. A multi-scale characterisation of the durum wheat pasta cooking process. Int. J. Food Sci. Technol., 54, 17131719, https://doi.org/10.1111/ijfs.14057

Marti A, Pagani M.A., 2013. What can play the role of gluten in gluten free pasta? Trends Food Sci. Technol., 31(1), 63-71, https://doi.org/10.1016/j.tifs.2013.03.001

Martinez C.S., Ribotta P.D., Leon A.E., Anon M.C., 2007. Physical, sensory and chemical evaluation of cooked spaghetti. J. Texture Studies, 38(6), 666-683, https://doi.org/ 10.1111/ j.1745-4603.2007.00119.x

Obuchowski W., 1997. Technology of industrial production of pasta (in Polish). Wydawnictwo Akademii Rolniczej im. Augusta Cieszkowskiego, Poznań.

Operation Manual, 1997. Texture Analyser TA.XT2 (in Polish). Stable Micro System.

Palavecino P.M., Bustos M.C., Heinzmann Alabi M.B., Nicolazzi M.S., Penci M.C., Ribotta P.D., 2017. Effect of ingredients on the quality of gluten-free sorghum pasta. J. Food Sci., 82(9), 20852093, https://doi.org/10.1111/1750-3841.13821

PN-93/A-74130: 1993. Pasta - sampling and methods of analysis (in Polish).

PN-A-74131: 1999. Pasta (in Polish).

PN-EN ISO 20483: 2014-02. Grain of cereals, seeds of legumes and their products - Determination of nitrogen content and conversion to protein content -Kjeldahl method (in Polish).

PN-EN ISO 2171: 2010. Grain of cereals, seeds of legumes and their products - Ash content determination with incineration method (in Polish).

PN-EN ISO 712: 2012. Grain of cereals and cereal products - Moisture determination - Reference method (in Polish).

Rafiq A., Sharma S., Singh B., 2017. In vitro starch digestibility, degree of gelatinization and functional properties of twin screw prepared cereal-legume pasta. J. Cereal Sci., 74, 279-287, https:// doi.org/10.1016/j.jcs.2017.03.001

Regulation of European Parliament and Council (EC) No, 1169/2011 of $25^{\text {th }}$ October, 2011, on providing consumers with information on food [Dz. Urz. UE L. 304(18)]. 
Romankiewicz D., Cacak-Pietrzak G., Gońda M., 2014: Estimation of quality of commercial fusilli type pasta (in Polish). Acta Agroph., 21(3), 327-335.

Rosell C.M., Barro F., Sousa C., Mena M.C., 2014. Cereals for developing gluten-free products and analytical tools for gluten detection. J. Cer. Sci., 59(3), 354-364, https://doi.org/10.1016/j. jcs.2013.10.001

Ruszkowska M., Nowicka K., 2017. Culinary evaluation of unconventional pastas (in Polish). Inż. Ap. Chem., 56, 5, 182-183.

Ruszkowska M., Rogowska O., 2015. Evaluation of culinary properties of selected gluten-free pastas (in Polish). Inż. Ap. Chem., 5, 277-278.

Schoenlechner R., Drausinger J., Ottenschlaeger V., Jurackova K., Berghofer E., 2010. Functional properties of gluten-free pasta produced from amaranth, quinoa and buckwheat. Plant Foods Hum. Nutr., 65, 339-349, https://doi.org/10.1007/s11130-010-0194-0

Sobczyk M., Glige K., 2012. Physical properties and chemical composition of wheat-buckwheat and buckwheat pastas (in Polish). Acta Agroph., 19(1), 143-153.

Sobota A., Skwira A., 2009. Physical properties and chemical composition of extruded pastas (in Polish). Acta Agroph., 13(1), 245-260.

Zandonadi R.P., Botelho R.B.A., Gandolfi L., Ginani J.S., Montenegro F.M., Pratesi R., 2012. Green banana pasta: an alternative for gluten-free diets. J. Acad. Nutr. Diet., 1068-1072, https://doi.org/ 10.1016/j.jand.2012.04.002

Zannini E., Jones J.M., Renzetti S., Arendt E.K., 2012. Functional replacements for gluten. Annu. Rev. Food Sci. Technol. 2, 227-245, https://doi.org/10.1146/annurev-food-022811-101203 